\title{
The Design of Cardiovascular System Model Equipment for Education
}

\author{
Doyeon Won ${ }^{*}$, Hongmoon Jung ${ }^{*}$, Jaeeun Jung*, Joonha Lee ${ }^{* *}$ \\ Department of Radiological Science, Daegu Health College*, \\ Department of Biomedical engineering, Yeung-Nam University ${ }^{* *}$

\section{심장 혈관계 시스템의 교육 모형 고안 \\ 원도연*, 정홍문*, 정재은*, 이준하**} \\ 대구보건대학교 방사선과*, 영남대학교 의공학과**
}

\begin{abstract}
The understanding of medical knowledge regarding cardiac shape and cardiovascular system is essentially required for a medical personnel as well as a medical technician. Correct acquisition of medical knowledge through cardiac miniature model is very critical because it is directly related to a patient life. therefore replica model is necessary for the education regarding cardiac and cardiovascular system. In this study anatomical cardiovascular system on fluoroscopy can be shown by cardiac and cardiovascular fluoroscopy replica model. Also, it helps to understand a cardiovascular radiograph. Consequentially medical personnel and medical technician are able to take advantage of this equipment to understand cardiovascular fluoroscopy system.
\end{abstract}

Keyword : cardiovascular, fluoroscopy, replica model, cardiovascular model.

\section{요 약}

심장의 모양 및 혈관에 관한 의료학적 지식습득은 의료인 및 의료기사들과 같은 의료전문인들에게는 필수적 요구 사항이다. 심장의 모형을 통한 의료지식의 습득은 환자의 생명과도 직결되는 중요한 사항이기 때문에 보다 정확한 의 료지식이 필요하다. 따라서 심장모양 및 심장혈관질환에 대한 다양한 의료교구재의 연구 및 개발이 필요하다. 이번 연 구에서 만들어진 심장 및 심장혈관의 투시 모형장비를 사용하여 심장 혈류의 투시조영시의 볼 수 있는 방사선학적 사 진 영상을 미리 습득할 수 있으며, 또한 투시 조영 중 환자의 자세의 따른 심장의 위치와 모형을 미리 예측해 볼 수도 있다. 결론적으로 우리가 고안한 심장혈관 투시 장비를 사용하여 심장혈관의 해부학적 지식을 미리 습득함으로서 면 허 취득 후에 임상생활에 있어서의 심장혈류에 관한 정확한 이해에 도움을 줄 수 있을 것으로 사료된다.

중심단어 : 심장혈관 모형, 심장혈관 교구재, 투시심장 모형, 심장혈관 투시모형 


\section{I. 서 론}

인체는 다양한 장기들로 구성되어있다. 인체의 질 병을 진단하고 연구함에 있어서 인체장기의 역할과 기능 및 모양을 습득하는 것은 질병을 진단함에 필수 적으로 요구되어진다. 인체의 해부 또는 장기의 모양 및 기능을 습득하고 연구함에 있어서 실물을 직접 보 고 다루어보는 것이 중요하지만 이러한 신체 장기는 공급의 한계와 같은 다양한 문제점을 가지고 있다. 이 를 보완하고자 현재 의료 교구재를 위한 장비들이 존 재한다 ${ }^{[1]-[3]}$. 의료인이나 의료기사분야 에서의 인체의 장기의 관한 기본적인 습득을 위해 배우는 과목은 인 체해부학, 인체생리학, 인체병리학 등 이 존재하며 이 러한 과목을 공부하여 신체 장기의 기본적인 구조를 파악하게 된다. 또한 해부학적 지식은 의료인 이외에 도 의료기사 2 년제부터 6년제 까지 많은 학과에서 학 생들에게 교육되어진다. 인체의 장기 모형은 해부학적 으로 다양한 모형이 존재하여 많은 교육 분야에서 사 용 중이다. 그러나 다양한 인체의 장기의 모형 중에서 심장의 혈관을 투시영상에서 보는 모형은 아직까지 연구되거나 개발되지 않은 것이 현실이다. 시대가 급 속도로 세계화됨에 따라서 서구 음식문화의 유입과 페스트 푸드의 보급 및 스트레스는 현대인으로 하여 금 다양한 심장 혈관 질환을 가져다주고 있다 ${ }^{[4]-[6]}$. 이 러한 이유 때문에 환자가 급속히 증가하고 있다. 임상 에서는 이러한 심장 혈관 질병을 치료하기위해 다양 한 중재적 시술이 시행되고 있다 ${ }^{[7]-[9]}$. 이러한 경우 C-Arm 과 같은 장비를 사용하여 심장의 동맥 또는 정 맥의 혈류상태를 투시하여 치료를 하는 경우가 대부 분이다 ${ }^{[10],[11]}$. 이에 맞추어 심장혈관의 실질적은 투시 영상을 얻고 치료계획을 세워 중재적 시술을 시행하 게 된다. 그러나 이러한 심혈관의 투시영상은 임상실 습 또는 방사선 사진을 통해서만 볼 수 있다는 단점을 가지고 있다. 이번연구는 모의 C-Arm 장비를 개발하 여 심장의 모양이나 심장의 흐르는 혈류를 직접이해 하고 해부학적 자세를 적용 시킬 수 있는 교육용 팬텀 을 개발하는데 중점을 두었다. 의료인이나 의료기사가 되고자하는 교육적 커리큘럼에서 사진으로 혹은 임상 실습에서만 보아야 하는 심장과 심혈관의 해부학적 모형과 위치를 투시영상에서 볼 수 있는 것과 같은 방
사선 사진을 구현하는데 중점을 두었다. 더 나아가서 심장혈관 투시 방사선사진을 환자의 해부학적 자세를 구현해 내고 유추 할 수 있는 모의 C-Arm과 환자의 해 부학적 위치에 따라 볼 수 있는 심혈관의 투시상황에 서의 혈관위치를 재현하고자 하였다. 마지막으로 이번 연구에서 개발한 모의 팬텀이 교육적인 자료로 충분 히 쓰일 수 있다는 자료로 재시하기 위해 설문조사를 통해 교육적 가치의 유효성을 조사하였다.

\section{II. 실험 및 방법}

\section{1. 실험장비 및 기구}

\section{1 교육모형개발}

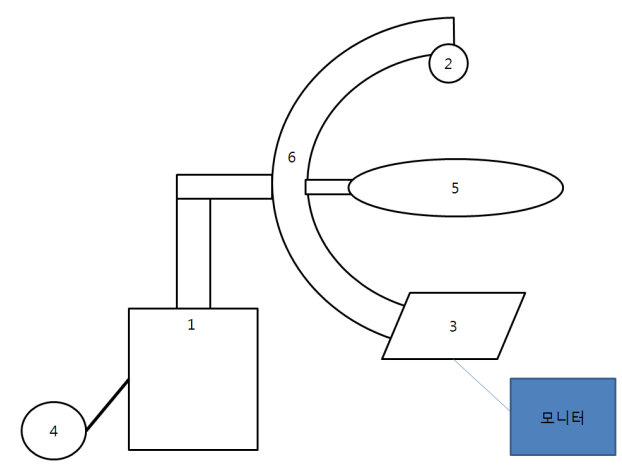

Fig. 1. Design of equipment.

국내에 사용 중인 장비의 대표적인 브랜드인 지멘 스, 필립스, $\mathrm{GE}$ 사의 혈관조영 및 중재적 시술장비를 모델로 하여 Fig. 1 과 같은 교육용 모델의 이미지를 설 계하였다.

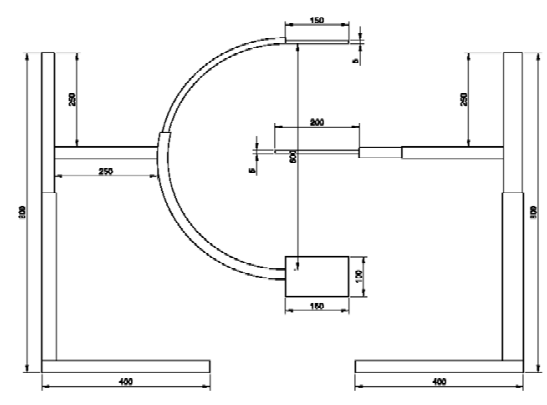

Fig. 2. System model blueprint. 
Fig. 1 의 이미지 설계를 바탕으로 하여 장비의 지지 장치, 튜브, 환자테이블 등의 위치를 파악하고 5:1로 축소한 각각의 사이즈를 바탕으로 Fig. 2와 같이 시스 템 모형으로 설계하였다.

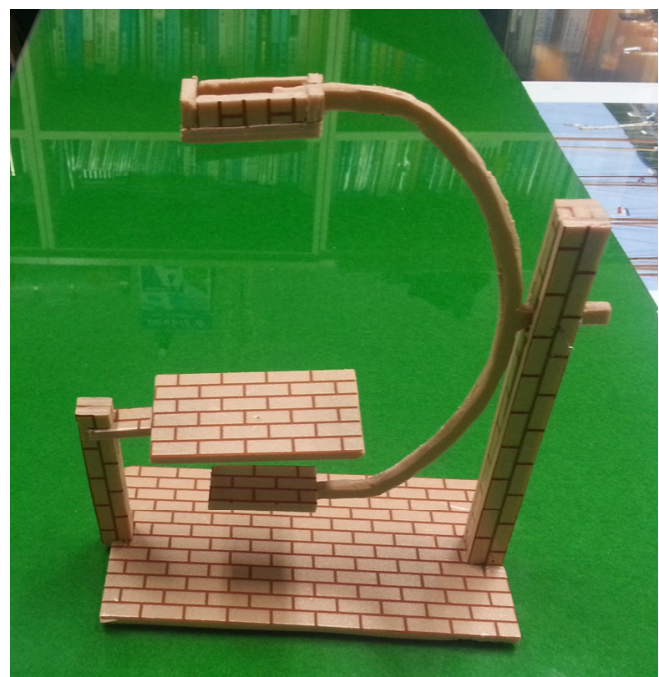

Fig. 3. Making of styrofoam replica model.

Fig. 2 의 설계도에 따라서 스틸로폼을 이용한 입체 모형을 제작하였다.

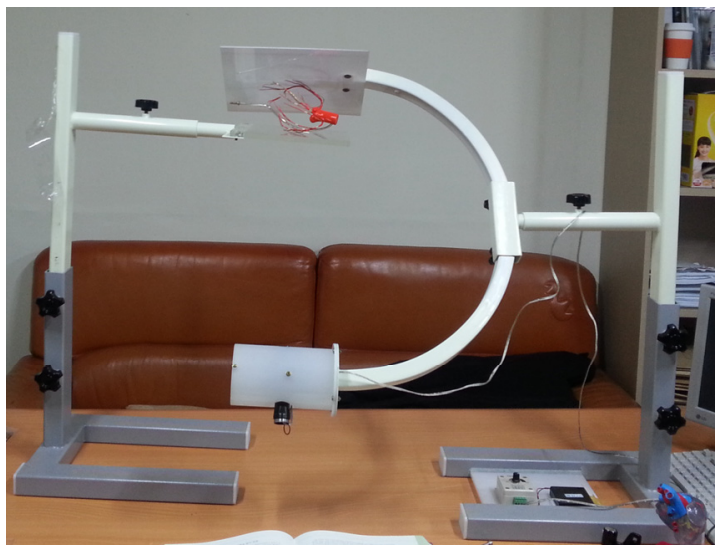

Fig. 4. Final skiagram equipment of cardiovascular system.

Fig. 3의 입체모형으로 실제 심혈관 검사의 매뉴얼 을 시뮬레이션 하였고, 그것을 기초로 Fig. 4 와 같은 교 육용모형을 제작하였다.
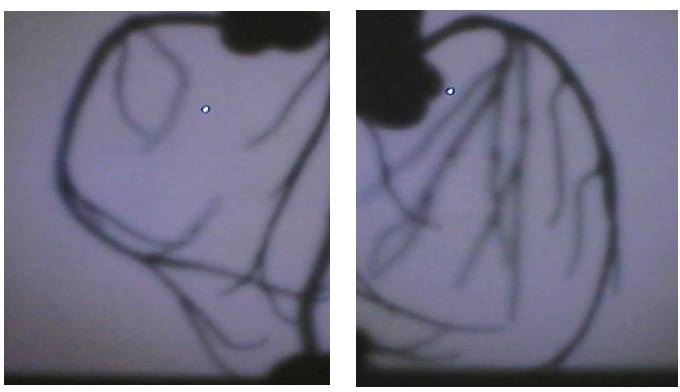

Fig. 5. sample of cardiovascular skiagram.

\section{2. 개발 모형의 제원}

\section{1 발생장치}

실제장비의 제네레이터는 건전지로, 튜브의 X선 조 사는 LED 광원장치를 이용한 빛의 투사로 하여 개발 하였다. 제네레이터는 $\mathrm{AA}$ 형 $1.5 \mathrm{~V}$ 건전지 4 개를 사용하 여 총 $6 \mathrm{~V}$ 의 전원 공급장치를 이용하였으며 빛의 밝기 는 가변저항을 이용하여 전류의 공급량을 조절하는 방법을 사용하였다. $\mathrm{LED}$ 광원장치는 모델명 $\mathrm{CREE}$ XML-U2 장착하였다.

\section{2 지지대}

튜브와 검출기가 있는 부분과 환자테이블이 있는 부분으로 제작하였다. 튜브 및 검출기가 있는 지지대 는 위쪽의 검출기와 아래쪽의 튜브를 지지하는 C-arm 을 본체의 지지장치와 상하좌우회전과 상하이동이 가 능하도록 기능적인 면을 추가하여 제작하였으며, 반대 쪽 환자테이블모형은 방사선은 인체를 투과하지만, 빛 을 이용하여 심장혈관을 나타내기 위해 아크릴판을 사용하여 제작하였으며, 실제장치와 같이 상하이동이 가능하도록 제작하였다. 회전 및 움직임기능에 있어서 는 고정장치는 고정형나사를 이용하였으며, 대부분의 재질은 철이며, 두가지 색으로 도색하였다.

\section{3 검출기}

심장동맥의 영상이 검출기의 투영되어 그림자로 묘 사될 수 있도록 흰색바탕의 이미지스크린으로 처리하 였다. 


\section{3. 교육모형의 평가}

평가는 표와 같이 설문지를 개발하여 전국 방사선 (학)과 혈관과 관련된 교수 5 명, 방사선과 학생 5 명으 로부터 각 5 점 척도로 평가를 받았다. 설문지 개발내 용은 모형의 와관, 회전검사, 상항이동검사, 전원공급 장치에 대한 평가 등을 포함하였다.

\section{※ 설문자에 관한 내용입니다.}

1. 귀하의 연령은 어디에 속하십니까?

(1) 20 대 (2) 30 대 (3) 40 대 (4) 50 대 이상

2. 귀하의 직업은 무엇입니까?

(1) 교 수 (2) 학생

3. 혈관계검사에 관하여 교육받은 적이 있습니까?

(1) 있다 (2) 없다

※ 교육용 모형에 관한 질문입니다.

4. 교육용모형을 이용한 simmulation에서

실제검사 장비와 비교하면 효율성은?

(1) 적당하다 (2) 거의 흡사하다

(3) 약간 부적절하다 (4) 부적절하다

5. 기기에서 나오는 광원의 조도는 어떻습니까?

(1) 적당하다 (2) 밝다

(3) 약간 어둡다 (4) 많이 어둡다

6. 교육모형에서 얻은 이미지는?

(1) 적당하다 (2) 거의 흡사하다

(3) 약간 부적절하다 (4) 부적절하다

7. 이미지의 분해능은 실제와 비교했을 때 어떻습니까?
(1) 적당하다
(2) 거의 흡사하다
(3) 약간 떨어진다 (4) 부적절하다

8. 이미지의 균일성은 실제와 비교했을 때 어떻습니까?

(1) 적당하다 (2) 거의 흡사하다

(3) 약간 떨어진다 (4) 부적절하다

9. 이미지의 대조도는 실제와 비교했을 때 어떻습니까?

(1) 적당하다 (2) 거의 흡사하다

(3) 약간 떨어진다 (4) 부적절하다

10. 교육용 모형의 동작은 어떻습니까?

(1) 쉽게 조절할 수 있다 (2) 대체로 쉬운 편이다
(3) 어렵다
(4) 많이 어렵다

11. 교육용모형의 전반적인 만족 평가와 활용도에 대해서 어떻게 생각하십니까?

(1) 만족하며, 활용가치가 있을 것으로 생각한다

(2) 만족하지만 보완점이 보인다

(3) 아이디어는 좋지만 실제 활용도는 낮을 것으로 보인다

(4) 전체적인 성능이 떨어지고, 활용도도 낮다

12. 기기에 대한 자유로운 의견을 제시해주십시오

\section{III. 결과}

\section{1. 설문지에 관한 분석결과}

\begin{tabular}{|c|c|c|c|c|}
\hline 문항 & (1) & (2) & (3) & (4) \\
\hline 1 & 2 & 4 & 4 & \\
\hline 2 & 5 & 5 & & \\
\hline 3 & 6 & 4 & & \\
\hline 4 & 5 & 5 & & \\
\hline 5 & 7 & 2 & 1 & \\
\hline 6 & 5 & 5 & & \\
\hline 7 & 6 & 3 & 1 & \\
\hline 8 & 4 & 4 & 2 & \\
\hline 9 & 3 & 5 & 2 & \\
\hline 10 & 5 & 5 & & \\
\hline 11 & 6 & 4 & & \\
\hline
\end{tabular}

20대 2명, 30대 4명, 40대 4명으로 구성된 교수 5명 및 학생 5 명으로부터 설문지를 받아보았다. 혈관계검 사에 대한 교육을 받은 사람은 6명, 받지 않은 사람은 4명으로 나타났으며, 교육용모형을 이용한 시뮬레이션 에서 실제 검사장비와 비교하였을 때 효율성은 적당 하다와 거의 흡사하다가 각각 5 명으로 나타났으며, 거 의 대부분의 질문이 적당하다와 거의 흡사하다는 평 가였다. 하지만 조도, 분해능, 균일성 및 대조도 부분 은 약간 부적절하다는 소수의 의견도 나타났다.

\section{2. 교육모형에 관한 분석결과}

설문지에 대한 분석결과를 토대로 교육모형에 대한 평가는 대부분 실제검사장비와 흡사하다는 평가였으 며, 교수들의 평가에서 조도, 분해능, 균일성 및 대조 도부분에서 약간 부적절하다는 평가가 있었다. 아울러 전반적인 만족평가와 활용도에 대해서는 대부분이 만 족하며, 활용가치가 있을 것으로 판단되었으며, 약간 의 보완점도 있어야 한다는 평가가 있었다.

\section{$\mathrm{IV}$. 결론 및 고찰}

다양한 인체 장기들 중에 심장의 중요성은 인체가 살아있는 원동력이기 때문에 중요하게 대두된다. 심장 의 모형을 통한 의료지식의 습득은 환자의 생명과도 
직결되는 중요한 사항이기 때문에 보다 정확한 의료 지식이 요구된다. 그중에서도 심장의 허혈성질환은 심 근 경색(cardiac infarction)과 같은 질병을 유발하여 환 자의 생명까지도 위협을 할 수 있다 ${ }^{[12]}$. 따라서 심장의 혈관과 혈류에 관한 의료학적 지식의 습득은 의료인 및 의료기사들과 같은 의료전문인들에게는 필수적인 사항으로 인지되어야 한다. 이번 연구에서 만들어진 심장혈관의 투시 모형장비를 사용하여 심장의 혈류의 투시조영시의 볼 수 있는 방사선학적 사진 영상을 미 리 습득할 수 있으며, 투시 조영중에 환자의 자세의 따른 심혈관의 위치를 미리 예측해 볼 수도 있다. 그 러나 몇 가지 보완사항이 있는데 설문조사에 따른 의 견을 제시하자면 각도조절시의 어려운 점, 외관상의 보완점등이 제시되었으며, 이는 앞으로 보완되어야 할 것으로 사료된다. 또한 이미지의 완전한 개선과 심혈 관뿐만 아닌 다른 장기를 적용시키는 팬텀을 사용하 여 인체장기적용의 다양성도 제시하여 교육용으로 한 층 더 보완된 장비개발을 해야 한다.

하지만 본 연구에서 고안된 장비는 충분한 교육적 가치를 가지고 있다는 의견이 더욱더 많다. 따라서 결 론적으로 우리가 고안한 심장혈관 투시 장비를 사용 하여 심장혈관의 모양을 미리 습득함으로서 면허 취 득 후에 임상생활에 있어서의 심혈관에 관한 정확한 이해에 도움을 줄 수 있을 것으로 사료된다.

\section{참고문헌}

[1] Yong Ok Kim, Youl Hun Seoung, "A Study on Various Automatic Exposure Control System in Multi-Detector Computed Tomography by Using Human Phantom", Journal of the Korea Academia-Industrial cooperation Society, Vol. 13, No. 4, pp. 1714-1720, 2012.

[2] Je Min Song, Gye Hwan Jin, Sung Bo Seo, Jeong Seok Park, Sang Bock Lee, et. al., "Design and Implementation of a Prediction System for Cardiovascular Diseases using PPG", Journal of the Korean Society of Radiology, Vol. 5, No. 1, pp. 19-25, 2011.

[3] Je il Lee, "Design \& Application of 3DM", CAD/CAM review ,Vol. 2, No. 1, pp. 26-32, 1996.

[4] Hae Kag Lee, Heung Joon Yoo, Sun Yeob Lee, Eun Hoe Goo, Jong Min Seok, et. al., "Protocol Optimization of Coronary CT Angiography", Journal of the Korean Society of Radiology, Vol. 5, No, 2, pp. 51-58, 2011.
[5] Mi Yon Lee, Sang Bock Lee, Jun Hang Lee, Sam Yul Lee, Tae Soo Lee, et. al., "Temporal Variations of Cerebrovascular Diseases in a University Hospital", Journal of the Korean Society of Radiology, Vol. 1, No, 1, pp. 17-23, 2007.

[6] Eun Young Kim, Ok Sang Lee, Sung Cil Lim, "Evaluation of Factors Affecting Glomerular Filtration Rate by Contrast Media in Patients with Coronary Angiography", Korean journal of clinical pharmacy, Vol. 22, No. 2, pp. 103-112, 2012.

[7] Byung Moo Choi, Keun Wha Lee, Samuel W. Kim, Bong Ha Lee, Dong Woon Choo, et. al., "Angiography with hypaque M utilizing Conventional X-ray Machine", Journal of the korean surgical society, Vol. 5, No 3, pp.169-175, 1963.

[8] Hong Do Cha, Un Moon, "Cardiac Catheterization and Angiocardiography", Korean Journal of Medicine, Vol. 16, No. 3, pp. 161-166, 1973.

[9] Mi Young Kim, Hwa Sun Kim, Shin Young Kim, "Association of Carotid Artery Intima-Media Thickness and Cardiovascular Risk Factors in Adult", Journal of radiological science and technology, Vol. 6, No.1, pp.25-30, 2013.

[10] Ho Chung Gyung, Hee Sohn Myung, Yong Lee Sang, Min Han Young, Soo Kim Chong, et. al., "Clinical Efficiency of Cardiovascular Interventional Procedure with Loop Snare Technique", Medical College of Chonbuk University, Vol. 1, No. 2, pp. 245-252, 1997.

[11] Yeoun Su Jung, Bong Ryeol Lee, Han Jun Ryu, Min Kyu Park, Min Hee Kim, et. al., "Relationship between Antiphospholipid Antibodies and Major Adverse Cardiovascular Events after Drug-Eluting Stent Implantation in Patients with Acute Myocardial Infarction", Korean Journal of Medicine, Vol. 84, No. 5, pp. 681-689, 2013.

[12] Soo Gyoung Han , Myung Ho Jeong, Jung Ae Rhee, Jin Su Choi, Kee Hong Lee, et. al., "Clinical Impact of High Triglycerides and Central Obesity in Patients with Acute Myocardial Infarction who Underwent Percutaneous Coronary Intervention", Korean Journal of Medicine, Vol. 86, No. 2, pp. 169-178. 2014. 